\title{
CUADERNOS
}

DE HISTORIA 54

DEPARTAMENTO DE CIENCIAS HISTÓRICAS

UNIVERSIDAD DE CHILE - JUNIO 2021: 373-387

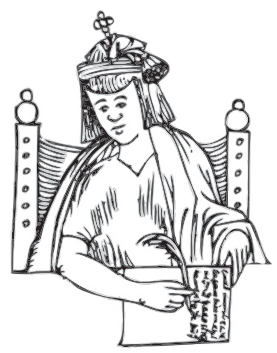

\section{UN DOCUMENTO INÉDITO DE MANUEL ANTONIO MATTA: APUNTES PARA SERVIR A LA BIOGRAFÍA DE FRANCISCO DE PAULA MATTA (1861)}

Claudio Soltmann Cáceres ${ }^{*}$

\begin{abstract}
RESUMEN: Este trabajo presenta una transcripción de un texto inédito escrito en 1861 por el político y escritor chileno Manuel Antonio Matta. El texto contiene apuntes sobre la vida y obra de su hermano mayor, el abogado y publicista chileno Francisco de Paula Matta, un escritor vinculado al movimiento literario chileno de la Generación de 1842.

Palabras Clave: Francisco de Paula Matta, Manuel Antonio Matta, literatura chilena, Generación de 1842, siglo XIX.
\end{abstract}

\section{AN unPUblished DOCUMENT by MANUEL ANTONio MatTa: Notes about THE BIOGRAPHY OF FRANCISCO DE PAULA MATTA}

ABSTRACT: This work presents a transcription of an unpublished text written by the Chilean politician and writer Manuel Antonio Matta in 1861. The text contains notes regarding the life and work of his older brother, the Chilean lawyer and journalist Francisco de Paula Matta, a writer associated with the Chilean Literary Movement known as the Generation of 1842.

KeYWords: Francisco de Paula Matta, Manuel Antonio Matta, Chilean Literature, Generation of 1842, XIX century.

Recibido: 25 de noviembre de 2020

Aceptado: 9 marzo de 2021

* Magíster en Estudios literarios y culturales latinoamericanos por la Pontificia Universidad Católica de Valparaíso, Pontificia Universidad Católica de Chile. Santiago, Chile. ORCID ID: https:// orcid.org/0000-0001-6044-6272. Correo electrónico: casoltma@uc.cl 


\section{Introducción}

Q e presenta aquí una transcripción de un texto inédito del político y escritor $\checkmark$ chileno Manuel Antonio Matta Goyenechea (1826-1892), que consiste en unos breves apuntes biográficos sobre la vida de su hermano mayor, el literato y abogado chileno Francisco de Paula Matta Goyenechea (1821-1854). Lamentablemente, todavía no se tiene certeza sobre a quién iba dirigido este texto, aunque las sospechas apuntan a que haya sido a un biógrafo y, probablemente, también amigo de Manuel A. Matta ${ }^{1}$. La autoría de este último en la redacción de estos apuntes evidencia la estrecha relación que mantenía con su hermano mayor. El vínculo entre hermanos quedó, además, patente en la "dedicatoria del traductor" que escribió Manuel Antonio en 1869 en el marco de su traducción, desde el alemán al castellano, del Fausto, de Johann Wolfgang von Goethe:

Las cuatro primeras estrofas en que Goethe mismo dedica su obra a personas que le eran queridas y ocupaban un gran lugar en su vida, aunque ya no lo tenían en la tierra, son un indicio, para aquellos que conocen al traductor y no han olvidado gratas amistades antiguas, de los motivos que él tiene, al inscribir, al frente de su trabajo, el nombre de F. de P. Matta; y el sentimiento que esas estrofas modulan poéticamente es una preparación y una justificación suficiente de lo que él se cree obligado a decir para explicar el significado de su dedicatoria, el objeto de su traducción y el carácter de la obra que interpreta ${ }^{2}$.

Se señala que Manuel Antonio Matta completó estos apuntes en enero de 1861 en la ciudad de Lima, a la que llegó luego de una breve estadía en Alemania durante 1859. Las razones del viaje a Perú se explican a causa de un frágil estado de salud de Manuel Antonio, quien padecía una enfermedad pulmonar grave, agudizada por el crudo invierno europeo ${ }^{3}$. Su destierro en Europa ocurrió durante la primera mitad de 1859, tras ser encarcelado en Chile a fines de 1858 por su participación en la Revolución del Colihue, donde se firmó una proclama por una nueva Asamblea Constituyente, atacando al poder ejecutivo. Estas acciones propiciaron la guerra civil de 1859 y Matta, junto con sus compañeros de la revuelta, recibió la condena de ser desterrado por las

Si bien, en 1874, Domingo Arteaga Alemparte publicó un texto biográfico sobre Francisco de Paula Matta, en el marco de un volumen de homenaje titulado "Suscrición de la Academia de BellasLetras a la estatua de don Andrés Bello", dicho texto no consigna ninguno de los datos que contienen estos apuntes biográficos de Matta. No hay certeza de que Arteaga Alemparte los haya revisado, ver Arteaga Alemparte, 1874, pp. 123-129.

Matta, 1907, p. 3.

No se encuentran todavía fuentes directas de Manuel Antonio Matta respecto al itinerario de su viaje. Sin embargo, su hermano menor, Guillermo Matta, quien se encontraba desterrado en ese momento en Berlín, le escribe a su amigo Marcial Martínez Cuadros, en una carta de noviembre de 1859, que "Manuel no ha recibido sus memorias porque ha partido para el Perú, en busca de los aires puros de la Tierra", Carta de Guillermo Matta a Marcial Martínez Cuadros, Berlín, 12 de noviembre de 1859, hoja 18380, Sala Medina, Biblioteca Nacional de Chile. 
autoridades de gobierno ${ }^{4}$. La ciudad de Lima, además, tenía un significado emocional para el autor, ya que fue allí donde Francisco de Paula había ido a buscar refugio a comienzos de 1854, luego de los acontecimientos de la guerra civil chilena de 1851 , para, desafortunadamente, encontrar la muerte al poco tiempo de llegar tras contraer la fiebre amarilla en marzo de ese mismo año.

\section{Contenido y estructura del documento}

Los apuntes sobre la vida de Francisco de Paula siguen un orden cronológico, señalando los años en que acontecen diversos hitos de su niñez; las clases particulares que recibió de parte de don José María Bórquez, un amigo de la familia, y los viajes de sus padres a Chiloé. También recoge datos respecto a su instrucción primaria en la escuela pública de la Villa de Copiapó, dependiente del fray Isidoro de la Barrera ${ }^{5}$, y su aprendizaje del latín bajo la supervisión de don Isidoro Mariano Zavalla, en compañía de dos de sus primos Gallo Goyenechea ${ }^{6}$. Los apuntes reconstruyen parte de la enseñanza primaria de algunos de los miembros de las familias de la elite minera copiapina durante las décadas de 1820 y 1830. En los apuntes se registra que Francisco de Paula fue testigo de la llegada a Copiapó, en 1831, de los prisioneros sublevados de la cárcel de la isla de Juan Fernández y del posterior saqueo de la ciudad 7 . En los años siguientes, Matta continuaría su enseñanza secundaria en la ciudad de Santiago, entrando al Colegio de Juan de Dios Romo, complejo educacional que se situaba en el claustro de la iglesia de la Merced de la capital. En 1839, Matta daría sus exámenes de latín y de filosofía, para luego tomar estudios de derecho romano y de latín en la casa de don Andrés Bello (1781-1865). Posteriormente, complementaría su formación de abogado con

4 Entre los otros condenados, figuran: Benjamín Vicuña Mackenna, Guillermo Matta Goyenechea, Ángel Custodio Gallo, Francisco Marín, Isidoro Errázuriz y Pedro León Gallo. Para un panorama histórico sobre estos acontecimientos, ver Ortega y Rubio, 2006; Fernández Abara, 2016. Para un retrato sobre la evolución de Manuel Antonio Matta como figura política desde la década de 1850, ver especialmente Ortiz González y Valenzuela Van Treek, 2014, pp. 21-24.

Sobre el fray Isidoro de la Barrera, el historiador Carlos María Sayagó señalaría que "nació en Valdivia en mayo de 1773 [...] profesó en la orden franciscana en el convento grande de Santiago y un año después recibió el grado de doctor en Teología en la Universidad de San Felipe. Tan pronto como se recibió del seminario en Copiapó, en mayo de 1803, reestableció la escuela de primeras letras que hacía algunos años se hallaba suprimida [...]. Preocupado siempre de la instrucción de la juventud, dio mayor impulso a la escuela del seminario, logrando más tarde establecer una clase de latinidad; en 1824 secularizó y fue llamado de Vallenar para dirigir una escuela municipal, volviendo en 1829 a Copiapó con igual objeto", Sayagó, 1874, pp. 282-283.

6 Es muy probable que se refiera a José Tomás Gallo Goyenechea (1822-1896), quien era un año menor que Francisco de Paula, y a José Manuel Gallo Goyenechea, nacido en 1818. Para más datos biográficos sobre la familia Gallo Goyenechea, principalmente sobre Miguel Gallo, ver Álamos Concha, 2007, pp. 13-23.

Se pueden encontrar algunas descripciones de estos acontecimientos en la ciudad de Copiapó, en Sotomayor Valdés, 1962, pp. 144-145. 
el aprendizaje de los idiomas francés e inglés, para, finalmente, obtener el grado de bachiller en leyes en el año 1842, otorgado por el Instituto Nacional.

Los apuntes nombran a gran parte de las amistades que construyó Francisco de Paula durante sus años de formación en la enseñanza secundaria en Santiago, tanto en la casa de Andrés Bello como en el Instituto Nacional, conectando su trayectoria con el relato del movimiento literario-intelectual chileno, de corriente "reformista y liberal", como fue el caso de la Generación de 1842. Por lo tanto, este documento constituye una adición relevante al corpus de fuentes primarias que permiten estudiar la construcción de redes intelectuales entre este círculo de jóvenes escritores y publicistas chilenos formados por Andrés Bello, como también en el marco de este movimiento político-literario ${ }^{8}$. En los apuntes se registran algunas de sus publicaciones más relevantes en la prensa de la época; por ejemplo, artículos críticos publicados en El Progreso y en El Mercurio de Valparaíso. Se suma también su trabajo como redactor de periódicos tales como El Siglo y El Crepúsculo entre 1842 y $1844^{9}$. Se mencionan sus vínculos con figuras relevantes en los círculos literarios de la época: Juan Nepomuceno Espejo Bravo (18211876), Francisco Bilbao (1823-1865), Jacinto Chacón (1820-1898), Francisco Solano Astaburuaga (1817-1892), Aníbal Pinto (1825-1884), Juan Bello Dunn (1825-1860), Cristóbal Valdés (1821-1853), Santiago Lindsay (1825-1876), entre otros. Asimismo, se describe brevemente su incipiente y truncada trayectoria como dramaturgo y poeta, aportando referencias de algunas de las obras que escribió entre los años 1842 y 1844; por ejemplo, los dramas Caupolicán, La independencia de Chile y El plebeyo, junto con la comedia Mi casa i país por den. En el caso de la poesía, aparece su colección Improvisaciones e impresiones. Lamentablemente, el documento indica que gran parte de estas obras escritas antes del mes de octubre de 1844 nunca se publicaron, debido a que fueron destruidas y mutiladas deliberadamente por su autor antes de viajar a Francia. Para evitar que ello ocurriera:

Antes de partir Francisco i cuando se estaba alistando para el viaje, lo encontré una mañana despedazando sus manuscritos i a las preguntas i observaciones que yo le hice, solo me respondió: ¡Vida nueva! i continuó en su injustificada tarea gracias 2011.

Para un recorrido histórico sobre el reformismo liberal de la Generación de 1842, ver Wood,

9 Entre sus publicaciones en El Crepúsculo destacan, especialmente, la crítica teatral a la obra Hernani, del escritor francés Víctor Hugo (1802-1885), publicada el 1 de junio de 1843; la crítica teatral que lleva el título "Boletín dramático", publicada el 1 de agosto de 1843, donde Matta desarrolla "una ojeada breve y filosófica" de las obras teatrales más importantes presentadas en Santiago -aquí publicó breves reseñas sobre las obras Antoni, Ricardo Darlington y Teresa, de Alexander Dumas (1802-1870)-; la comedia El pelo de la dehesa, del dramaturgo español Manuel Bretón de los Herreros (1796-1873), y el drama María Estuardo, del poeta alemán Friedrich Schiller (1759-1805), cuya autoría Matta no identifica en la reseña. Finalmente, resalta su estudio literario sobre el poeta del primer romanticismo español José de Espronceda y Delgado (1808-1842), publicado el 1 de marzo de 1844. 
a la cual desaparecieron sus trabajos de 4 años excepto los versos i artículos ya publicados $^{10}$.

El documento, más adelante, describe parte del viaje de Francisco de Paula junto con sus hermanos Manuel Antonio y Guillermo, a Francia en octubre de 1844, en compañía de Francisco Bilbao ${ }^{11}$. Este viaje a Europa se explica, principalmente, a raíz de la fuerte polémica que aconteció en Santiago tras la publicación del texto Sociabilidad chilena de parte de Bilbao; el artículo produjo una airada y virulenta reacción en los sectores cercanos a la Iglesia católica, que terminó con un juicio por blasfemia ${ }^{12}$. Francisco de Paula iba a representar legalmente a Bilbao en el juicio, sin embargo, desistió de hacerlo días antes del juicio, decisión que atribuyó a la enfermedad de su padre. Estas razones fueron informadas a través de una carta publicada en el periódico El Siglo ${ }^{13}$. Tras llegar a París, en marzo de 1845, es muy probable que Francisco de Paula haya emprendido una travesía por diversas regiones francesas hasta 1846, pero este hecho no se menciona en los apuntes ${ }^{14}$. Más adelante, se consigna una breve marcha por Bélgica, también en 1846. Al año siguiente, viajaría durante la primavera a la ciudad de Berlín para visitar a su hermano Manuel Antonio. Posteriormente, en verano de ese mismo año, emprendería, junto con su hermano Manuel, una travesía desde Viena, por el Danubio, hasta al mar Negro, llegando a Constantinopla (Estambul), para finalmente cruzar el mar Egeo hasta Grecia y luego viajar a Italia.

Tras su regreso a Chile en 1849, Francisco de Paula retoma su trabajo como editor y redactor de la recientemente fundada Revista de Santiago, labor que desempeñó hasta 1851. En ese período además se destacaría como un activo colaborador en sus páginas, publicando varias poesías y traducciones ${ }^{15}$. La colaboración periodística y

10 Apuntes para servir a la biografía de Francisco de Paula Matta, p. 3.

11 En la correspondencia de Francisco Bilbao con Félicité Robert de Lammenais, encontramos la siguiente nota: "Manuel Antonio Matta, su hermano Francisco de Paula y Francisco Bilbao se embarcaron el 6 de octubre de 1844, y al parecer en París alquilaron juntos un departamento en la rue Martignac, no 7, tercer piso”, ver García San Martín y Mondragón, 2013, p. 191.

12 Sobre la polémica suscitada por la publicación del texto Sociabilidad chilena, de Francisco Bilbao, ver Stuven, 2000.

13 Francisco de Paula señalaría en esta carta: "Como abogado y como amigo yo iba a ser el defensor del Sr. Bilbao en la acusación interpuesta ante el jurado. Llegará el día, y el abogado no estará junto a su noble amigo. Pero si me atrevía a correr lo que el vulgo llama un peligro y los devotos un sacrificio, he titubeado cuando aparecieron a mi vista la salud quebrantada de un padre que aprecio y las ternuras de su corazón". F. de Paula Matta, "Una satisfacción”, El Siglo, N 65, Santiago, 19 de junio de 1844.

14 Si bien en los apuntes no hay detalles sobre sus recorridos por Francia, Francisco de Paula Matta publicó en la Revista de Santiago el poema "Yambos. El bautismo del honor (M. F. Fernández de Rodella)", que firmó en la ciudad francesa de Rennes en 1846.

15 La Revista de Santiago publicó en 1850 algunos de sus textos escritos durante sus viajes por Europa entre 1845 y 1849. El primero fue "Marcha Turca (de Víctor Hugo)", que trata de una breve traducción desde el francés de un poema de temática "orientalista". A ella se suman las traducciones de dos poemas del escritor alemán J. W. von Goethe (1749-1832), titulados "A la luna" y "Dios y la bayadera". También se publicó una traducción del soneto "El llanto de Laura. Soneto 123", del poeta 
amistad con Andrés Ricardo Bello (hijo de don Andrés Bello) en la publicación de $E l$ Picaflor en 1849 también marca un hito en el desarrollo de las letras nacionales. Al final del documento, influenciado posiblemente por su viaje por Grecia, se menciona el intento de Francisco de Paula de traducir desde el francés la colección poética Los orientales, de Víctor Hugo ${ }^{16}$. Sin embargo, la tarea de traducción quedaría truncada con su fallecimiento repentino, por fiebre amarilla, en marzo de 1854.

En suma, a pesar de su temprano deceso, el recorrido biográfico de Francisco de Paula Matta presentado en este documento, lo posicionaría como un personaje de amplia relevancia en el marco del estudio de la historia de la crítica literaria en Chile durante la década de 1840, como también en la historia política e intelectual del período. Dar a conocer estos apuntes biográficos inéditos resulta necesario, puesto que clarifican diversos aspectos de su vida, a la vez que aportan nuevos detalles de su formación como escritor, en teatro y en poesía, y como traductor, también sobre su amplia red colaborativa en el ejercicio del periodismo nacional durante las décadas de 1840 y 1850.

El manuscrito se encuentra en el Fondo Sergio Fernández Larraín del Archivo Nacional de Chile. El editor de la transcripción agradece la disposición de la institución para la consulta, reproducción y publicación del documento. Se ha decidido mantener la ortografía original del texto, los subrayados son del original y se ha editado el formato de la numeración de los años para otorgar una mejor orientación de las fechas. Todas las notas al pie del manuscrito son de autoría del editor.

aretino Francesco Petrarca (1304-1374), y de una selección de versos de la obra teatral Marco Visconti, del autor italiano Tomasso Grossi (1790-1853), que Matta tituló “Canto de un trovador". Finalmente, se publicó un fragmento poético de su autoría, titulado "Nápoles".

16 Les Orientales es una colección de poemas del escritor francés publicada en 1829. La temática de estos poemas se encuentra influenciada por los acontecimientos de la independencia de Grecia. 
Imagen 1. Fotografía de la primera foja del documento

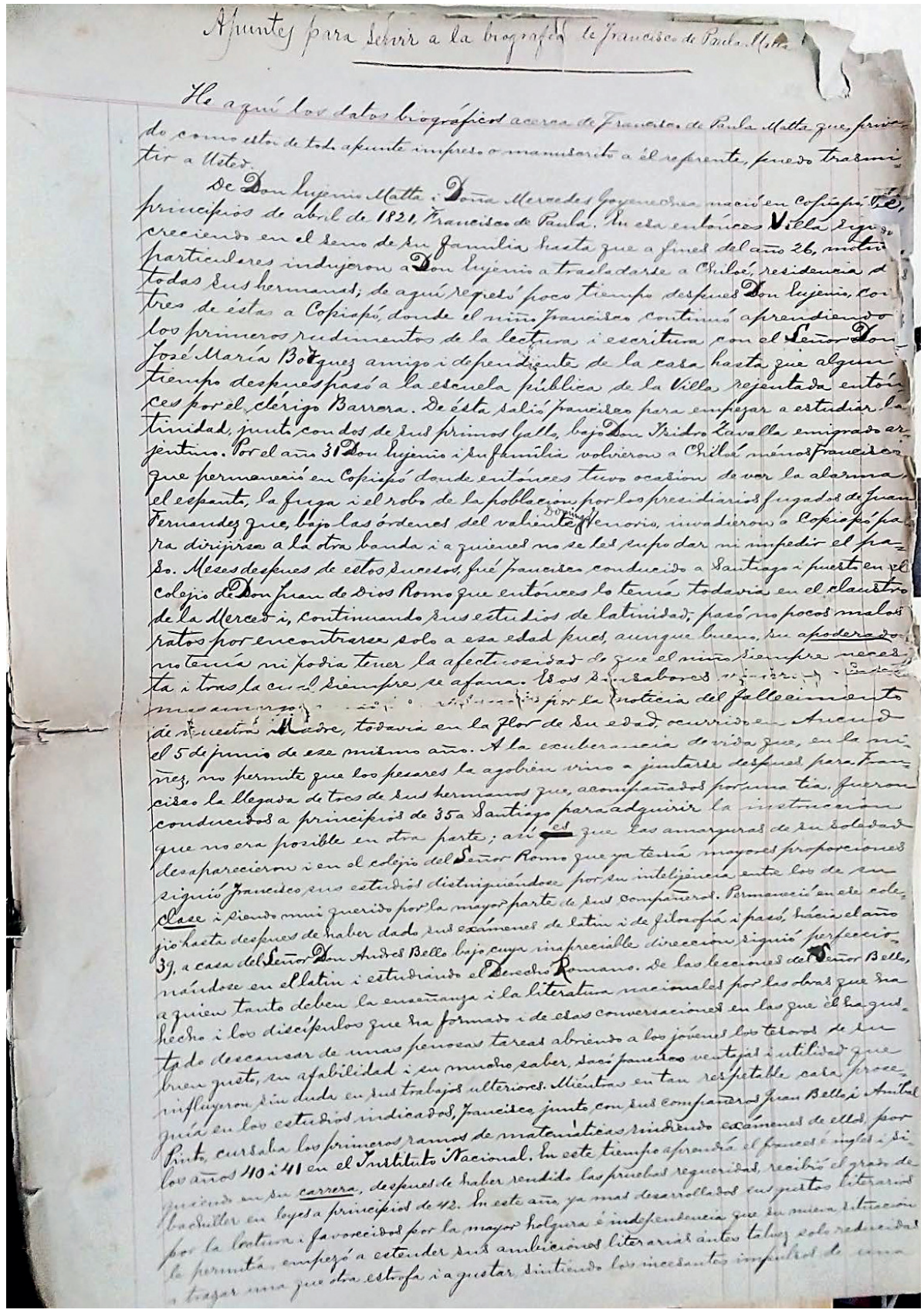




\section{Documento}

Apuntes para servir a la biografía de Francisco de Paula Matta.

He aquí los datos biográficos acerca de Francisco de Paula Matta que, privado como estoi de todo apunte impreso o manuscrito a él referente, puedo transmitir a Usted.

De Don Eujenio Matta i Doña Mercedes Goyenechea nació en Copiapó [a] principios de abril de 1821, Francisco de Paula. En ese entónces Villa $[\ldots]^{17}$, creciendo en el seno de su familia, hasta que a fines del año [18]26 moti[vos] particulares indujeron a Don Eujenio a trasladarse a Chiloé, residencia d[e] todas sus hermanas; de aquí regresó poco tiempo después Don Eujenio, con tres de éstas a Copiapó, donde el niño Francisco continuó aprendiendo los primeros rudimentos de la lectura i escritura con el Señor Don José María Borquez, amigo i dependiente de la casa hasta que algún tiempo después pasó a la escuela pública de la Villa, rejentada entónces por el clérigo Barrera. De ésta salió Francisco para empezar a estudiar latinidad, junto con dos de sus primos Gallo ${ }^{18}$, bajo Don Isidro Zavalla emigrado arjentino. Por el año [18]31 Don Eujenio i su familia volvieron a Chiloé, menos Francisco que permaneció en Copiapó donde entónces tuvo ocasión de ver la alarma, el espanto, la fuga i el robo de la población por los presidiarios fugados de Juan Fernández, que, bajo las órdenes del valiente Domingo Tenorio, invadieron a Copiapó para dirijirse a la otra banda i a quienes no se les supo dar ni impedir el paso. Meses después de estos sucesos, fue Francisco conducido a Santiago i puesto en el Colejio de Don Juan de Dios Romo que entónces lo tenía todavía en el claustro de la Merced i, continuando sus estudios de latinidad, pasó no pocos malos por encontrarse solo a esa edad pues, aunque bueno, su apoderado no tenía ni podía tener la afectuosidad de que el niño siempre necesita i tras la cual siempre se afana. Esos sinsabores $[\ldots]$ más amargo $[\ldots][\ldots]^{19}$ por la noticia del fallecimiento de nuestra madre, todavía en la flor de su edad, ocurrido en Ancud el 5 de junio de ese mismo año. A la exuberancia de vida, que en la niñez, no permite que los pesares la agobien vino a juntarse después, para Francisco la llegada de tres de sus hermanos que, acompañados por una tía, fueron conducidos a principios de [18]35 a Santiago para adquirir la instrucción que no era posible en otra parte; así es que las amarguras de su soledad desaparecieron, i en el colejio del Señor Romo, que ya tenía mayores proporciones, siguió Francisco sus estudios distinguiéndose por su intelijencia entre los de su clase i siendo mui querido por la mayor parte de sus compañeros. Permaneció en ese colegio, hasta después de haber dado sus exámenes de latín i de filosofía, i pasó, hacia el año [18]39, a casa del Señor Don Andrés Bello bajo cuya inapreciable dirección siguió perfeccionándose en el latín i estudiando el Derecho Romano. De las lecciones del Señor Bello, a quien tanto deben la enseñanza i la literatura nacionales por las obras que ha hecho i los discípulos que ha formado, i de esas conversaciones, en las que él ha gustado descansar de unas penosas tareas abriendo a los jóvenes los tesoros de su buen gusto, su afabilidad, i su mucho saber, sacó Francisco ventajas

17 Ilegible. Borde de la hoja se encuentra rasgada.

18 Es muy probable que se trate de José Tomás Gallo Goyenechea y José Manuel Gallo Goyenechea.

19 Ilegible. Lamentablemente los trazos de tinta se han borrado a causa de un doblez en la página del documento. 
i utilidad que influyeron sin duda en sus trabajos ulteriores. Miéntras, en tan respetable casa, proseguía en los estudios indicados, Francisco, junto con sus compañeros Juan Bello ${ }^{20}$ i Aníbal Pinto ${ }^{21}$, cursaba los primeros ramos de matemáticas rindiendo exámenes de ellos, por los años [18]40 i [18]41 en el Instituto Nacional. En este tiempo, aprendía el francés é inglés i siguiendo en su carrera, después de haber rendido las pruebas requeridas, recibió el grado de bachiller en leyes a principios de [18]42. En este año, ya más desarrollados sus gustos literarios por la lectura i favorecidos por la mayor holgura é independencia que su nueva situación le permitía, empezó a estender sus ambiciones literarias ántes talvez solo reducidas a trazar una que otra estrofa i a gustar, sintiendo los incesantes impulsos de una

legitima emulación de las obras de los antiguos poetas españoles i de los modernos escritores franceses. Aunque sociales, jovial i amistoso, Francisco trabajaba en silencio i no sé que otros que nuestro amigo Juan José Hernández, Don Francisco S. Asta-Buruaga ${ }^{22}$ tuviesen conocimiento entónces de sus proyectos i sus tentativas de composición literaria. Una de las primeras materias, fuera de un artículo sobre el Instituto, en $[\ldots]^{23}$ se ejercitó su pluma, fue el teatro, ya trazando juicios críticos sobre la compañía i las piezas dramáticas las cuales deben hallarse en el "Mercurio" de [18]42 i [18]43 y escribiendo una trajedia i una comedia las que, escritas en prosa, debian después, al modo que lo practicaron Juan W. Goethe $^{24}$ a veces, Víctor Alfieri ${ }^{25}$ siempre, ser puestas en verso. La trajedia que nunca puso en verso titulábase "Caupolicán" i solo por el nombre se colije que la conquista habría sido su terreno a Alonso de Ercilla el instigado de éste sin embargo no habría tomado otra cosa que los nombres de los personajes i uno que otro rasgo del carácter del héroe. La acción, harto sencilla, se desenvolvía entre Caupolicán, Guacolda, Reinoso, un sacerdote i dos o tres personajes secundarios. La resistencia al invasor era la base de la trajedia, resistencia que se manifestaba, en Caupolicán, por el odio a los españoles, en Guacolda, por el desden del amor, de Reinoso que pretendrá por toda clase de medios vencer o castigar su repugnancia, contribuyendo, él con la maldad, i ella con su desapego, al fatal desenlace, el suplicio de Caupolicán, final de la trajedia que era preparado i harmonizado en las creencias comunes por la conversión del indómito araucano arrojando así un resplandor de grandeza sobre Caupolicán i el sacerdote i un reflejo mas siniestro de ódio sobre Reinoso, aborrecible como amante i como hombre. La comedia, versificada a ejemplo de los dramaturgos españoles, con variedad de metros, se titulaba "Mi casa i país por den" i tenía por objeto poner en escena la lucha entre el entusiasmo i el ódio ciegos por lo extranjero. Servíase para esto de unos pocos personajes, un francés truhan, de quien protegido por la deschavetada de la madre $\mathrm{i}$

\footnotetext{
20 Juan Bello Dunn (1825-1860), poeta y diplomático chileno. Fue el primer hijo de Andrés Bello e Isabel Antonia Dunn.

21 Aníbal Pinto (1825-1884), político y abogado chileno. Presidente de la República entre 1876 y 1881. En 1846 inició su carrera diplomática formando parte de la delegación chilena a Roma.

22 Francisco Solano Astaburuaga (1817-1892), político, diplomático y escritor chileno.

23 Palabra ilegible, borde de la hoja se encuentra rasgada.

24 Johann Wolfgang von Goethe (1749-1832), poeta, dramaturgo, novelista y científico alemán.

25 El conde Vittorio Amadeo Alfieri (1749-1803), dramaturgo, poeta y escritor italiano.
} 
atacado por el no ménos deschavetado, en sentido contrario, de un tio, se enamoraba i casi llegaba a casar una bella niña que había tenido mas gusto en casarse, como al fin lo hacía, con un chileno compañero de ella desde, su infancia. Muchas de las escenas de esta comedia reflejaban de un modo mui natural i mui a lo vivo, costumbres, ideas i aun preocupaciones nacionales de esa época que fué la ajitacion precursora de movimiento i progreso en mas de una de las esferas de la actividad social.

Sin descuidar sus ocupaciones de bachiller, sin huir de las cuestiones políticas ni desdeñar los gratos momentos de relaciones amicales, continuaba Francisco sus tentativas literarias i, fuera de algunas composiciones, líneas, compuso un drama con algunas escenas en verso, titulado "Aurora”, del nombre de la heroína cuyo asunto era el amor, pero funesto en sus consecuencias, por la rivalidad i los célos. Los incidentes i los personajes eran de los tiempos modernos i toda la acción i su desarrollo reflejaban mas de lo que el autor mismo podía sospecharlo, algo de la literatura dramática francesa de 25 años há.

Sin enumerar prolijamente algunos artículos publicados en el "Progreso" del año [18]43 sobre "Elecciones de la Universidad", "18 de Setiembre", i otros sin su firma ni de muchas composiciones impresas allí mismo i firmadas, compuso otro drama titulado "La Independencia de Chile" en el cuál el carácter i el amor de dos jóvenes, alrededor de quiénes se agrupaban otros personajes, servían para representar la encarnizada é inconciliable lid entre la Metrópoli i su Colonia, entre lo nuevo i lo viejo, entre el espíritu de servidumbre i él de libertad que conmovía tan fuertemente nuestro país en los años [18]14 i [18]18. Don Cárlos, el protagonista, era de los insurjentes i de aquí provenían todos los obstáculos al acebrado amor que su adorada pagaba con el mismo ardor. El diálogo de los representantes de las distintas ideas, el choque

de las opuestas opiniones i el eco de los acontecimientos que se realizaban fuera del círculo de la familia dividida i en guerra como la Nación, iban sucesivamente mostrando todas las fases de la lucha que, habiendo comenzado, con el grandioso paso de los Andes i mil rayos de heroísmo, concluía en favor de la libertad i del porvenir por la fecunda batalla de Maipú.

Por éste tiempo, junto con su amigo don Aniceto Chacón ${ }^{26}$ que había sido su compañero en la práctica forense, tomó Francisco el grado de licenciado i fué luego nombrado defensor de pobres habiendo entónces solamente ejercido i mui rara vez la profesión de abogado a la que no tuvo nunca mucha afición. Estimulados por la presencia de algunos escritores arjentinos que ocupaban todos la prensa, los jóvenes de la generación, en que descollaban Lastarria, los Bello, Sanfuentes, Tocornal i otros, fundaron el "Semanario" cuyo lugar, habiendo dejado de aparecer, vino a tomar el "Crepúsculo" redactado i fundado por varios otros jóvenes entre quienes estaba Francisco i de los que recordaremos a Lastarria, Espejo ${ }^{27}$,

26 Hermano de Jacinto Chacón. También se dedicó a la composición de poesía.

27 Juan Nepomuceno Espejo Bravo (1821-1876), político y publicista chileno. 
C. Valdez ${ }^{28}$, los dos Chacón ${ }^{29}$, Fco Bilbao, Juan Bello, Asta-Buruaga i Lindsay ${ }^{30}$ a quienes prestaba su importante auxilio Don A. Bello con sus concienzudos trabajos acerca de filosofía i acerca de literatura.

Inútil creo decirle a Usted nada mas respecto al movimiento literario de esos tiempos pues le será fácil i mas provechoso i agradable seguirlo en las publicaciones de entónces; fuera de que sería alegrarme demasiado ocuparme de la parte que Francisco i los demas tomaron en esa ajitación literaria mirada tan de reojo por algunos retardatarios. Formando proyectos mas atrevidos entró Francisco a ser dueño de la "Imprenta del Crepúsculo" junto con Juan N. Espejo i Santiago Urzúa i queriendo los tres influir más directamente en la política i en la sociedad fundaron el diario el "Siglo" que comenzó a aparecer el 5 de abril de 1844 i cuya redacción en jefe correspondió a Francisco hasta fines de junio de ese año, época en que por arreglos hechos en la "Imprenta", pasó el diario a otras manos. En éste mes tuvo lugar el ruidoso jurado por el artículo "Sociabilidad chilena" publicado en el Crepúsculo" cuyo autor, Francisco Bilbao, fue condenado el 20 de junio i a quien, fuera de las multas impuestas, creyó la "Universidad" deber imponer mas rencoroso i estúpido castigo. Buena cosecha de disgustos tuvo en estos acontecimientos Francisco quien, mui a pesar suyo, tuvo que renunciar a ser el defensor de su amigo acusado como puede Usted verlo en una carta publicada en el (Siglo) tres o cuatro días antes del famoso jurado ${ }^{31}$.

Sin desmayar en sus trabajos literarios continuó con mas fervor Francisco i fruto de ellos fue otro drama que, en su título revela ya las ideas que preocupaban su espíritu. Titulábase el drama el "Plebeyo", i su escena pasaba en Lima, en tiempos de no sé qué Virrei, siendo el argumento enteramente ideal. Yo no leí esta pieza, pero recuerdo, por relación de mi hermano, que el fondo era el antagonismo de la aristocracia i la democracia.

Nuestro Padre, que había pensado siempre mandar a Francisco a completar su educación a Europa, decidió mandarnos en principios de octubre. Antes de partir Francisco i cuando se estaba alistando para el viaje, lo encontré una mañana despedazando sus manuscritos i a las preguntas i observaciones que yo le hice, solo me respondió: ¡Vida nueva! i continuó en su injustificada tarea gracias a la cual desaparecieron sus trabajos de 4 años excepto los versos i artículos ya publicados, la "Aurora" que estaba en poder de un amigo al principio de una leyenda en verso, i el de una novela nacional. En la tarde del 6 de éste mes, aunque tristes con la despedida, llenos

de esperanzas en el porvenir i anhelantes de saber, salimos de Valparaíso en la fragata norte-americana "Seaman" junto con nuestro amigo Fco Bilbao. Hicimos rumbo a Montevideo i estuvimos diez días en esa pintoresca ciudad entonces sitiada por el atroz

28 Cristóbal Valdés (1821-1853), abogado y escritor chileno.

29 Mención a los hermanos Jacinto y Aniceto Chacón.

30 Santiago Lindsay (1825-1876), publicista y servidor público chileno.

31 La carta de Matta se tituló “Una satisfacción”, El Siglo, № 65, 19 de junio de 1844. 
i ridiculo Coriolano José María Oribe ${ }^{32}$, dirijiéndonos en seguida a Rio-Janeiro en donde permanecimos unos veinte días admirando la belleza i la variedad de sus indescriptibles paisajes. De Rio nos embarcamos para el Hâvre adonde llegamos a mediados de febrero de [18]45. De aquí fuimos a París donde permaneció mi hermano hasta el verano de [18]46 en que hizo una escursión a Bélgica regresando luego a Paris, centro de un buen número de americanos entre los cuales habría un grupo de chilenos, llegados con la legación cerca de Roma, la mayor parte de los cuales eran amigos de Francisco, siéndolo principalmente José María Gallo, Felipe Herrera, el secretario i Aníbal Pinto el primer oficial de la legación. Con estos amigos pasó Francisco hasta la primavera de [18]47 época en la cual partió para Alemania donde debía juntarse conmigo para hacer juntos un viaje a Grecia por Constantinopla. Llegó Francisco a Berlín a mediado del verano, i por Viena, el Danubio i el Mar Negro nos dirijimos a Constantinopla donde paramos unos veinte días admirando su naturaleza siempre encantadora i recorriendo los sitios que las obras de arte o los notables sucesos de la historia antigua i moderna recomendaban a nuestra ávida contemplación. Cruzando esos mares i a la vista de esos lugares que chispean recuerdos poéticos é históricos llegamos al Pireo, puerto de Atenas, después de haber hecho más de 20 días de cuarentena en Sira. En Atenas permanecimos unos pocos días, durante los cuales, en los ratos de descanso, Francisco puso término, escribiendo la introducción a la colección de sus poesías que con el título de "Improvisaciones e impresiones" había de publicar por entonces nuestro compatriota don Narciso Cueto. Por motivos que no es del caso referir, esta impresión no se hizo, i en ella muchos se habrían sorprendido de hallar antiguas composiciones de Francisco transformadas, correjidas i mutiladas sin piedad, según él decía, por respeto al público. De Aténas, de la cual se dice bastante con decir su nombre, pasando por Corinto i cruzando después el histórico golfo de Lepanto, nos encaminamos a Italia i desembarcamos en Ancona, para de allí irnos a Roma donde se encontraba F. Herrera ${ }^{33}$ quien a causa de una peligrosa enfermedad que inspiraba mui sérios cuidados, a Francisco no lo había acompañado en su viaje a Oriente. Llegamos a Roma a principios de diciembre, i tuvo el dolor de encontrar a su amigo F. Herrera ya tan enfermo que ni esperanzas podía tener, según decía el mismo paciente, de llegar siquiera a morir a las costas de Chile. En efecto, su fallecimiento ocurrió a mediados de enero de [18]48 i después de haber cumplido con los encargos i la voluntad de su malogrado amigo, cuyo recuerdo trató de perpetuar en su poema titulado "Memorias de un muerto", del cual quedan algunos fragmentos, Francisco partió para Nápoles i, repasando después por Roma en la época de la revolución francesa de febrero, dio vuelta a Francia i en su camino tuvo ocasión de ver el entusiasmo, la carencia de medios materiales de guerra i las faltas de los políticos que explican el levantamiento i la caída de Italia en [1]848, juntándonos en Paris, yo, viniendo de Berlín, i él de Milán, i despues de haber presenciado las funestas jornadas de junio, en julio nos dirijimos a Londres para, embarcarme yo con destino a Chile, i Francisco a España: lo que no realizó principalmente por llegar antes del período electoral a Chile, donde comenzaban a ajitarse los espíritus al soplo de las ideas que estaban conmoviendo i que aun conmueven a Europa.

32 Es posible que se refiera al militar y político uruguayo Manuel Ceferino Oribe y Viana (17921857). Oribe estableció un sitio en Montevideo desde 1843 hasta 1851.

33 Felipe Herrera trabajaba en ese momento como secretario de la Legación chilena en Roma. 


\section{A fines de Enero de [18]49 llegó Francisco a Chile é incitado por las circunstancias,}

por los amigos i por sus propios sentimientos é ideas, coadyugó a la redacción de algunos periódicos políticos i literarios de ese entónces sosteniendo las opiniones i candidatos de la oposición. Del número de esos periódicos el mas conocido es el "Corsario" publicado despues de las elecciones, muchos artículos del cual eran atribuidos a Francisco por el mismo autor tal vez que los habia redactado con intenciones de ofender. La marcha que el periódico iba tomando i la conducta de algunos de sus corredactores no influyeron poco en la resolución de Francisco para retirarse del "Corsario" aprovechándose para ello, a fines de mayo, de las subidas al ministerio de los S. D. Tocornal ${ }^{34}$ i D. García Reyes ${ }^{35}$. Fue despues de esto, asiduo colaborador del elegante periódico literario publicado por nuestro amigo Andrés Ricardo Bello ${ }^{36}$, "El Picaflor" i a principios del [18]50 se hizo cargo Francisco de la redacción de la "Revista de Santiago" publicado por el mismo intelijente editor. Disgustos é incomodidades le atrajo naturalmente ésta redacción, que abarca en poco mas de un año, el movimiento político del cual nació al fin la sangrienta lucha de 1851 i 52 . No perteneciendo Francisco al uno ni al otro bando habló con independencia i libertad hasta que, convencido de que era imposible conservar estas en la prensa, se encerró en el silencio haciendo votos porque la dolorosa crisis del país fuese lo ménos costosa i siguiera fecunda en buenos resultados para el porvenir. Llegadas las elecciones de [18]52 pensó Francisco presentarse como candidato a la diputación en uno de los departamentos de Chiloé para donde creyó poderse embarcar en un "Vapor" que sabía en esa época; pero esto no solo le fué imposible sino que la administración resolvió i conmovió las dos únicas provincias que habían permanecido tranquilas por impedir su elección i la de otros dos. Las tropelías del gobierno montt-varista ${ }^{37}$ que prometía ya ser lo que ha sido: uno de los más funestos, indujeron a Francisco a hacer un reclamo ante la Cámara i que para no oír ni una palabra contraria a sus jefes lo rechazó, sin leerlo, dos veces, obligando así al autor en la tercera únicamente la enumeración de los escandalosos abusos cometidos que había de envolver el acostumbrado silencio.

Estando pues la prensa esclavizada, la sociedad oprimida i, en jeneral, los corazones de todos adoloridos o enconados, Francisco prosiguió dando pábulo a la actividad de su alma, herida pero no agobiada por la luctuosa situación del país, en sus trabajos literarios entre los cuales ocupaba el primer lugar una colección de composiciones poéticas, patrióticas

34 Manuel Antonio Tocornal (1817-1867) asumió en 1849 el Ministerio de Justicia, Culto e Instrucción pública en el gobierno de Manuel Bulnes.

35 Antonio García Reyes (1817-1855) asumió en 1849 el Ministerio de Hacienda en el gobierno de Manuel Bulnes.

36 Andrés Ricardo Bello (1826-1869), poeta chileno, segundo hijo de Andrés Bello e Isabel Antonia Dunn.

37 El uso del adjetivo "montt-varista" de parte de Manuel Antonio Matta hace referencia a la dupla de Manuel Montt y Antonio Varas. Principales promotores del Partido Nacional fundado en 1857 tras la Cuestión del Sacristán. 
é históricas a la cual había dado el nombre de "Rimas de rimas". Para visitar a algunos parientes i amigos i acompañar a nuestro hermano Felipe ${ }^{38}$, partió Francisco a mediados de [18]53 con destino a Copiapó i después de haber residido allí algunos meses, ocupado en concluir una traducción ya mui adelantada de las Orientales de Víctor Hugo i en trazar, o continuar, trabajos suyos, se embarcó para Lima en compañía de su buen amigo A. R. Bello. Apénas habían llegado a esa ciudad declaróse la fiebre amarilla i entre las numerosas víctimas de la epidemia se contó a Francisco fallecido en la madrugada del 18 de marzo de [1]854 en brazos de Francisco Bilbao i rodeado de algunos otros de nuestros compatriotas que habían acudido a acompañarlo. Los periódicos chilenos de abril i mayo de [18]54 contienen algunas palabras sobre nuestro finado hermano de quién, para darle a Usted todos los datos literarios, solo me falta decirle que su último trabajo, en el cuál parecía estarse ocupando cuando enfermó, era una obrita sobre "Instrucción pública" de la que alcanzó a escribir casi toda la introducción i a bosquejar el número i la materia de los principales capítulos que habían de componerla. ¡Ojalá estos descarnados apuntes ofrezcan a Usted los datos que deseaba i esperaba!

\author{
M. A. Matta \\ Lima, enero 14 de 1861.
}

\title{
Bibliografia
}

Álamos Concha, Pilar (ed.), Epistolario de Miguel Gallo Goyenechea 1837-1869, Santiago, Centro de Investigaciones Diego Barros Arana, 2007.

Arteaga Alemparte, Domingo, "Francisco de Paula Matta", Suscrición de la Academia de Bellas-Letras a la estatua de don Andrés Bello, Santiago, Imprenta de la Librería del Mercurio, 1874, pp. 123-129.

Fernández Abara, JoAquín, Regionalismo, liberalismo y rebelión: Copiapó en la guerra civil de 1859, Santiago, Ril Editores, Escuela de Historia, Universidad Finis Terrae, 2016.

García San Martín, Álvaro y Rafael Mondragón, “Correspondencia de Francisco Bilbao con Lamennais, Quinet y Michelet. (trad. Alejandro Madrid Zan)", Anales de Literatura Chilena, $\mathrm{N}^{\circ}$ 20, Santiago, 2013, pp. 187-282.

Matta, Manuel Antonio, “Dedicatoria del traductor”, en Juan W. Goethe, Fausto. Traducido al castellano por Manuel Antonio Matta, Santiago, Imprenta Barcelona, 1907.

Ortega Martínez, Luis y Pablo Rubio Apiolaza, "La guerra civil de 1859 y los límites de la modernización en Atacama y Coquimbo", Revista de Historia Social $y$ de las Mentalidades, Vol. 2, № 10, Santiago, 2006, pp. 11-39.

38 Felipe Santiago Matta Goyenechea (1824-1876), empresario minero de Copiapó. 
Ortiz González, Edison y Esteban Valenzuela Van Treek, "Infante y Matta: Entre la disidencia y la cooptación. El fracaso del federalismo en el siglo XIX", Cuadernos de Historia, $\mathrm{N}^{\circ}$ 41, Santiago, 2014, pp. 7-32.

Sayagó, Carlos María, Historia de Copiapó, Copiapó, Imprenta de El Atacama, 1874.

Sotomayor VALDÉs, RaFAel, Historia de Chile bajo el gobierno del general don Joaquín Prieto I, Santiago, Academia Chilena de la Historia, Fondo histórico presidente Joaquín Prieto, 1962.

StUVEn, ANA María, La seducción de un orden. Las elites y la construcción de Chile en las polémicas culturales y políticas del siglo XIX, Santiago, Ediciones Universidad Católica de Chile, 2000.

Wood, James A., The Society of Equality. Popular Republicanism and Democracy in Santiago de Chile, 1818-1851, Albuquerque, University of New Mexico Press, 2011. 
